\title{
Physicochemical, antioxidant and in-vitro release behaviour of burfi added with curcumin as a source of functional ingredient
}

\author{
Gote Shubham Dattatraya, Writdhama Prasad and Kaushik Khamrui
}

Received: 19 December 2019 / Accepted: 17 April 2020 / Published online: 12 July 2020

(C) Indian Dairy Association (India) 2020

\begin{abstract}
The present study was conducted to explore the benefits of curcumin and to enhance the antioxidant potential of burfi. Three different forms of curcumin viz. native curcumin, curcumin emulsion, and dried curcumin encapsulate powder were added to burfi. Addition of curcumin in burfi resulted in significant $(\mathrm{P}<0.05)$ increase in the antioxidant potential. A highest antioxidant potential with minimal decrease in the sensorial and colour attributes was observed in dried encapsulate added at patting stage. The functional properties were enhanced with the extent of dried curcumin encapsulate in burfi. The in-vitro study revealed that encapsulated curcumin was the most suitable form for addition in burfi as $63 \%$ of curcumin retention was observed after intestinal digestion. Curcumin encapsulate added burfi was found effective against fungal spoilage-causing microorganisms due to the reduction of $0.35 \mathrm{Log}$ CFU/ml Aspergillus flavus and 0.47 Log CFU/ml Aspergillus niger. The available curcumin restricts the growth of spoilage-causing microorganisms and thus extends the shelf life of curcumin encapsulate added burfi by 3 days when stored at $30 \pm 1^{\circ} \mathrm{C}$. Thus, curcumin in the form of dried encapsulate was found to be effective for enhancement of antioxidant potential and shelf life of burfi.
\end{abstract}

Keywords: Antioxidant, Burfi, Curcumin, Shelf life, Sensory attributes

Dairy Technology Division, ICAR-National Dairy Research Institute, Karnal, 132001 Haryana, India

Kaushik Khamrui $(\bowtie)$

Dairy Technology Division, ICAR-National Dairy Research Institute, Karnal, 132001 Haryana, India

Email: kkhamrui@gmail.com; Mob: +919991883555

\section{Introduction}

Turmeric (Curcuma longa L.) is a herbal plant that belongs to the ginger family, originated and grown in the Indian subcontinent. Curcumin is the bioactive component present in turmeric, comprise of about $3-5 \%$ of total rhizome and is responsible for the yellow colour (Jayaprakasha et al. 2006). It has a wide array of functional attributes viz., antioxidant, antimicrobial, antifungal, neuroprotective and anticarcinogenic activity and over the past few years, there has been an increasing interest in curcumin due to its medicinal properties (Maheshwari et al. 2006). Curcumin possess Generally Recognized As Safe (GRAS) status by the FDA for food applications. Despite of many benefits, the lipophilic nature of curcumin limits its application in many of the food products, thus restricts the exploration of all benefits of this bioactive compound. In addition to its solubility, the lower bioavailability, another critical issue which hinders its application in food products (Kakkar et al. 2011).

To explore the functional benefits of curcumin, extensive research has been carried out to enhance its water solubility and stability to make it available for food application. Many novel technologies like complexation, emulsion, and encapsulation were used to protect curcumin from harsh processing conditions, makes it more stable, mask undesirable taste and enable it for food application (Madene et al. 2006). Encapsulation is the promising technology to protect bioactive components and it is extensively used in dairy as well as in the food industry. The various phytochemicals have been successfully encapsulated using nanoemulsions (Garti, 2003). Spray-drying is considered as an effective technique for encapsulating curcumin in milk system as being a fat soluble substance, curcumin gets entrapped with fat globules inside a solid mix of lactose and protein and thus protected against harsh processing condition during food application (Neves et al. 2019). Despite of many successful preparations of curcumin emulsion and encapsulates, only a few researchers have studied the actual behaviour of prepared curcumin emulsion in dairy products. Lodh et al. (2018) reported that ghee with enhanced antioxidant property and overall sensorial acceptability could be prepared by incorporation of curcumin. 
Burfi is one of the most popular traditional khoa based sweet prepared by heat desiccation of milk followed by the addition of sugar. However, it is highly susceptible to the chemical as well as microbial spoilage (Prasad et al. 2017b). With increased demand, the lower shelf life imparts an additional burden on the dairy industry. Thus, addition of naturally occurring bioactive compounds such as curcumin to improve functionality and shelf life. The incorporation of curcumin in burfi not only enhances its shelf life but also contributes to better human health of consumer due to the beneficial health attributes of curcumin. Thus, the present work has been undertaken with the objective of application of encapsulated curcumin as a source of functional ingredient in burfi to enhance its antioxidant potential and shelf life and its comparison assessment with native curcumin added burfi.

\section{Materials and Methods}

\section{Materials}

Fresh milk was procured from the Experimental Dairy of the ICARNational Dairy Research Institute, Karnal, India and was standardised to $6 \%$ fat and 9\% SNF using Pearson's square method. Curcumin powder with $93.03 \%$ total curcuminoids was procured from M/s Plant Lipids Pvt. Ltd. Kolenchery, Cochin, Kerala. Whey protein-80 (WPC- 80) was procured from M/s Globex Enterprises, Delhi, India. Maltodextrin (maximum 20.00\% reducing sugar) and Gum acacia were procured from $\mathrm{M} / \mathrm{s}$ HiMedia Laboratories Pvt. Ltd., Mumbai. Butteroil was prepared from cream containing $80 \%$ fat and $2.3 \%$ SNF obtained from Experimental Dairy, National Dairy Research Institute, Karnal using direct evaporation method (De, 1989). Partially concentrated skimmed milk with $13.85 \%$ total solids was taken from Experimental Dairy, National Dairy Research Institute, Karnal.

\section{Preparation of oil-in-water $(\mathrm{O} / \mathrm{W})$ curcumin emulsion}

The curcumin emulsion $(\mathrm{O} / \mathrm{W})$ was prepared in three stages using the method described by Meena (2018). In the first stage, the core phase was prepared by solubilisation of curcumin in butteroil with continuous stirring at $60^{\circ} \mathrm{C}$ for $10 \mathrm{~min}$ with the help of magnetic stirrer. In second stage, the wall phase was prepared by mixing 1:2 parts of protein (WPC-80) and carbohydrate (maltodextrin and gum acacia in $90: 10$ proportions) in partially concentrated skimmed milk. In third stage, the core material (oil phase) and the wall material were properly mixed using a blender and the emulsion was prepared by high-speed homogenisation using Ultra-Turrax mixer at $10,000 \mathrm{rpm}$ at $60^{\circ} \mathrm{C}$ for $10 \mathrm{~min}$. In the final stage to dried curcumin encapsulate was prepared by spray drying the emulsion at $180^{\circ}$ and $85^{\circ} \mathrm{C}$ inlet and outlet air temperature, respectively.

\section{Effect of different processing conditions on emulsion stability}

The stability of curcumin emulsion was tested against diverse processing conditions like $\mathrm{pH}$, ionic concentration, and heat treatment using the method described by Sari et al. (2015) with certain modifications. For effective heating, $10 \mathrm{ml}$ emulsion was taken in test tubes and subjected to different heat treatments viz., pasteurization $\left(63^{\circ} \mathrm{C}\right.$ for $\left.30 \mathrm{~min}\right)$ and boiling $\left(95^{\circ} \mathrm{C}\right.$ for 10 min). The effect of $\mathrm{pH}$ was assessed by adjusting the $\mathrm{pH}(3,6$ and 9) of emulsion using either $0.1 \mathrm{~N} \mathrm{HCl}$ or $0.1 \mathrm{~N} \mathrm{NaOH}$ solution. A different concentration of salt $(0.35 \mathrm{M}, 0.70 \mathrm{M}$, and $1 \mathrm{M} \mathrm{NaCl})$ was added to prepare the emulsion with different ionic concentration. After exposing to the above mentioned treatment, the stability of curcumin emulsion was evaluated on the basis of particle size distribution, viscosity and zeta potential using Master sizer 3000 version 3.30 (Malvern Instruments Ltd, Malvern, Worcs WR14)).

\section{Preparation of burfi}

The control burfi was prepared using the standard batch method as proposed by Bhatele (1983). During the preparation of curcumin burfi, different forms of curcumin viz., native curcumin (free form), curcumin emulsion, and dried curcumin encapsulate powder in quantity equivalent to $100 \mathrm{ppm}$ free curcumin (100 ppm native curcumin, 25\% liquid emulsion, and 10\% dried curcumin encapsulate on khoa basis) were added separately at different stages of burfi preparation (initially in standardized milk, after the first boil, initially in milk along with sugar, and at patting stage).

\section{Antioxidant potential and total phenolic content}

The antioxidant potential of control and curcumin added burfi was evaluated by DPPH (2, 2 diphenyl-1-picryl hydrazyl) method given by Brand-Williams et al. (1995). $0.1 \mathrm{~mL}$ of prepared methanolic extracted sample solution was mixed with $2.9 \mathrm{~mL}$ of freshly prepared DPPH working solution in amber coloured test tube and was properly vortexed and incubated in dark at $37^{\circ} \mathrm{C}$ for $30 \mathrm{~min}$. After incubation, absorbance of the solution was measured spectrophotometrically at $517 \mathrm{~nm}$. For blank, $0.1 \mathrm{~mL}$ methanol was taken instead of the sample.

ABTS [2, 2'-azinobis (3 ethyl benzothiazoline) -6-sulfonic acid] free radical scavenging activity of control as well as curcumin added burfi was evaluated by the method given by Re et al. (1999). $0.1 \mathrm{~mL}$ of prepared sample solution was mixed with $3.9 \mathrm{~mL}$ of ABTS working solution and incubated in dark at $37^{\circ} \mathrm{C}$ for 6 min. After incubation, absorbance of the solution was measured spectrophotometrically at $734 \mathrm{~nm}$. For blank, $0.1 \mathrm{~mL}$ methanol was taken instead of the sample.

Inhibition $($ per cent $)=\frac{(\text { Blank absorbance }- \text { Sample absorbance })}{\text { Blank absorbance }} \times 100$ 
Total phenolic content of burfi samples (control and curcumin burfi) were analysed by Folin-Ciocalteu's method of Maizura et al. (2011) with slight modification. $0.4 \mathrm{~mL}$ of methanolic extracted sample solution was mixed with $2 \mathrm{~mL}$ of $0.2 \mathrm{~N}$ Folin Ciocalteu's phenol reagent. After 3 minutes, $1.6 \mathrm{~mL}$ of sodium carbonate solution $(7.5 \%)$ was added into it and incubated at $37^{\circ} \mathrm{C}$ for $2 \mathrm{hr}$. The absorbance was measured spectrophotometrically at 730 nm.

\section{Estimation of curcumin retention in burfi}

The curcumin retention in burfi was estimated according to the method of ASTA(1985) with slight modification. Exactly, $1 \mathrm{~g}$ of burfi sample was mixed with $10 \mathrm{~mL}$ of $95 \%$ ethyl alcohol and mixed thoroughly using pestle and mortar to facilitate colour extraction. The solution was subjected to centrifugation at 4000 rpm for 30 minutes followed by filtration through $0.22 \mu$ syringe filter. The absorbance of filtrate was measured at $425 \mathrm{~nm}$.

\section{Colour analysis}

Colour measurement of burfi samples was estimated using HunterLab model Colour Flex ${ }^{\circledR}$ (Mini Scan XE plus, Hunter Associates Laboratory Inc. Reston, Virginia, U.S.A.) and the results were expressed in terms of CIE-LAB ( $L^{*}, a^{*}$ and $\left.b^{*}\right)$ system.

\section{Sensory evaluation}

Control and curcumin added burfi samples were organoleptically evaluated on a 9-point hedonic scale by a panel of semi-trained judges selected from the Faculty of Dairy Technology Division.

\section{Texture analysis}

The texture profile analysis of burfi sample $(1 \mathrm{~cm}$ height and $1 \mathrm{~cm}$ in diameter) was evaluated using TA-XT2i Texture Analyzer (M/ s Stable Micro Systems, UK) using P75 Probe, test speed of 1 $\mathrm{mm} / \mathrm{s}$, Compression of $80 \%, 25 \pm 1^{\circ} \mathrm{C}$ testing temperature, Load cell $25 \mathrm{~kg}$.

\section{In vitro release kinetics of encapsulated curcumin added burfi}

In-vitro release kinetics of encapsulated curcumin burfi was evaluated under simulated gastrointestinal conditions as per protocol given by Herrero-Barbudo et al. (2009).

\section{Microbial analysis}

For microbial analysis, Total plate count, coliform count, yeast and mould count were determined by the standard procedure given by Indian Standards IS: SP: 18(Part XI)-1981.

\section{Physicochemical analysis}

The free fatty acids (FFA) content of burfi was estimated using the method of Deeth and Fitz-Gerald (1975). Total Hydroxy Methyl
Furfural (HMF) content in burfi was determined by the method recommended by Keeney and Bassette (1959).

\section{Antifungal activity}

Fungal cultures NCDC-224 (Aspergillus niger) and NCDC- 226 (Aspergillus flavus) were subjected for proper activation by three subculturing. Curcumin burfi $(11 \mathrm{~g})$ was properly mixed in $99 \mathrm{~mL}$ saline solution added with $100 \mu \mathrm{L}$ fully activated fungal culture and allowed to react with curcumin present inside burfi for $4 \mathrm{~h}$. The subsequent plating was performed by standard protocol given in Indian Standards IS: SP: 18 (Part XI)-1981.

\section{Statistical analysis}

Data obtained from various experiments were recorded as mean \pm standard error (SE) and were subjected to analysis of variance (ANOVA) using Tukey's post hoc comparison test to establish the significance of differences among the mean values at 5 per cent level of significance by employing SPSS statistical package.

\section{Results and Discussion}

\section{Characterization and process stability of curcumin nanoemulsion}

The effect of process conditions on emulsion stability was evaluated in terms of particle size distribution, zeta potential, and viscosity and the results are presented in Table 1 .

\section{Effect of pH}

The particle size and zeta potential were significantly affected with change in $\mathrm{pH}$ of emulsion, while the viscosity showed a non-significant difference between all the $\mathrm{pH}$ adjusted emulsions. The emulsion adjusted to $\mathrm{pH} 3$ was completely destabilized with increased particle size to $1603.67 \mathrm{~nm}$ (Figure 1) and reduction in zeta potential to $-0.313 \mathrm{mV}$. This could be due to coagulation and aggregation of milk proteins with the decrease in $\mathrm{pH}$ caused due to the shifting of electrical charge on particles that result in the reduction of electrostatic repulsive forces between protein molecules. A similar trend was observed by Sari et al. (2015) in curcumin nanoemulsion adjusted to $\mathrm{pH} 3$ where the zeta potential was significantly reduced from -6.9 to $+2.03 \mathrm{mV}$. Rao and Mcclements (2011) studied the effect of processing conditions on nano/microemulsions and found destabilization and aggregation of emulsion at lower $\mathrm{pH}$ values, which was attributed to the reduction of electrostatic repulsive forces.

\section{Effect of heat treatment}

Heat treatment $\left(63^{\circ} \mathrm{C} / 30 \mathrm{~min}\right)$ caused a slight change in the particle size and zeta potential, but the destabilization effect was significantly higher in extremely heated emulsions $\left(95^{\circ} \mathrm{C} / 10 \mathrm{~min}\right)$ with increased particle size to 1099.83 (Figure 2) while the zeta 
potential decreased to $-16.84 \mathrm{mV}$. A tremendous increase in viscosity from 16.57 to $1623.33 \mathrm{mPa}$.s was observed in boiled emulsion $\left(95^{\circ} \mathrm{C} / 10 \mathrm{~min}\right)$. The destabilizing effect was associated with the denaturation and aggregation of whey proteins due to intense heating that destroyed the native structure of the emulsion. Sari et al. (2015) reported a slight increase in the particle size of curcumin nanoemulsion after pasteurization $\left(63^{\circ} \mathrm{C} / 30 \mathrm{~min}\right)$ that increased with increased heat treatment $\left(95^{\circ} \mathrm{C} / 10 \mathrm{~min}\right)$.

\section{Effect of ionic concentration}

A non-significant difference in the viscosity of curcumin emulsion was observed in comparison to control emulsion due to variation in ionic concentration, but the zeta potential and particle size distribution were significantly affected. The average particle size was increased to $394.43 \mathrm{~nm}$ at $1 \mathrm{M} \mathrm{NaCl}$ concentration (Figure 3). A non-significant difference in zeta potential was observed in control curcumin emulsion $(-20.97 \mathrm{mV})$ and emulsion added with $0.35 \mathrm{M} \mathrm{NaCl}(-20.20 \mathrm{mV})$, but with increased ionic concentration to $1 \mathrm{M} \mathrm{NaCl}$ a significant decrease in the zeta potential to -17.73 $\mathrm{mV}$ was observed. This could be due to the alteration in the repulsive forces between the proteins at higher salt concentration. Sari et al. (2015) reported a significant alteration in the zeta potential of curcumin nanoemulsion with changes in ionic concentration.

\section{Effect of a different form of curcumin and stages of addition on free radical scavenging activity (ABTS and DPPH) and total phenolic content of burfi}

The results of the antioxidant activity and total phenolic content of burfi added with different forms of curcumin at various stages of preparation are presented in Table 2. The ABTS and DPPH free radical scavenging activity of burfi was significantly increased with the addition of curcumin. Antioxidant activity of both emulsion and dried encapsulate added burfi was significantly higher than native curcumin added burfi. The increase in antioxidant potential of encapsulation was observed as compared with native curcumin added burfi, with an approximate 25 to 30

Table 1 Effect of processing conditions on emulsion stability $\mu \mathrm{g}$ Trolox equivalent (depends on the stage of addition). The different stages of curcumin addition had a significant effect on antioxidant potential with the highest activity observed in burfi added with curcumin encapsulate at patting stage. The total phenolic content in curcumin added burfi was significantly affected by different forms of curcumin. The highest phenolic content was found in burfi added with liquid curcumin emulsion at patting stage. The lowest antioxidant potential and phenolic content of native curcumin added burfi could be due to the interactive effect of curcumin and milk constituents that decreased the curcumin concentration in burfi. The hydrophilic and hydrophobic interactions were the binding force behind the complexation of polyphenolic compounds and caseins (Pan et al. 2014). Encapsulation protects curcumin and restricts its interaction with casein, thus enhances the potential functional benefits of curcumin. Addition of curcumin encapsulate at patting stage caused less destabilization of curcumin encapsulate (due to heating and stirring) thus results in minimal interaction with milk solids. Pan et al. (2014) observed the interaction of curcumin with casein micelles that limits the actual functional benefits of curcumin when added in milk system. Bourassa et al. (2013) also reported the interaction of casein ( $\alpha$-casein and $\beta$-casein) with curcumin and other polyphenolic compounds when added in the milk system.

\section{Effect of a different form of curcumin and stages of addition on curcumin stability in burfi}

The effect of different form of curcumin and stages of addition on curcumin stability in burfi were compared and listed in Table 2. Emulsion and dried curcumin encapsulate added burfi retained significantly higher amount of curcumin (approximately 90\%) than native curcumin added burfi. Among all the stages, the highest curcumin retention was observed at patting stage. The results indicate the resistance of encapsulation against the interaction of curcumin and milk components due to the shielding effect of the coating material. A same shielding effect of the coating material against the interaction of curcumin and milk components was observed by Maurya (2012), who prepared curcumin-

\begin{tabular}{|c|c|c|c|}
\hline Treatment & $\begin{array}{l}\text { Average particle } \\
\text { size distribution }(\mathrm{nm})\end{array}$ & $\begin{array}{l}\text { Zeta potential } \\
(\mathrm{mV})\end{array}$ & $\begin{array}{c}\text { Viscosity } \\
\text { (centipoises) }\end{array}$ \\
\hline Untreated emulsion (pH- 6.5) & $155.70 \pm 10.51^{\mathrm{a}}$ & $-20.97 \pm 0.44^{\mathrm{b}}$ & $16.57 \pm 0.78^{\mathrm{a}}$ \\
\hline $\mathrm{pH}-3$ & $1603.67 \pm 16.90^{\mathrm{e}}$ & $-0.31 \pm 0.04^{\mathrm{e}}$ & $13.03 \pm 0.29^{\mathrm{a}}$ \\
\hline $\mathrm{pH}-9$ & $505.80 \pm 47.35^{\mathrm{c}}$ & $-24.50 \pm 0.26^{\mathrm{a}}$ & $12.57 \pm 0.09^{\mathrm{a}}$ \\
\hline Ionic concentration $0.35 \mathrm{M} \mathrm{NaCl}$ & $382.03 \pm 34.69^{b c}$ & $-20.20 \pm 0.57^{b}$ & $12.37 \pm 0.32^{\mathrm{a}}$ \\
\hline Heat treatment $\left(63^{\circ} \mathrm{C} / 30 \mathrm{~min}\right)$ & $286.77 \pm 21.47^{\mathrm{ab}}$ & $-19.60 \pm 0.40^{\mathrm{bc}}$ & $20.97 \pm 0.75^{a}$ \\
\hline Heat treatment $\left(95^{\circ} \mathrm{C} / 10 \mathrm{~min}\right)$ & $1099.83 \pm 54.54^{\mathrm{d}}$ & $-16.84 \pm 0.29^{d}$ & $1623.33 \pm 8.82^{b}$ \\
\hline
\end{tabular}

Values are Mean \pm standard error $(n=3)$

a,b,c,d,e: Mean with different superscripts are significantly different within the column $(\mathrm{p}<0.05)$ 


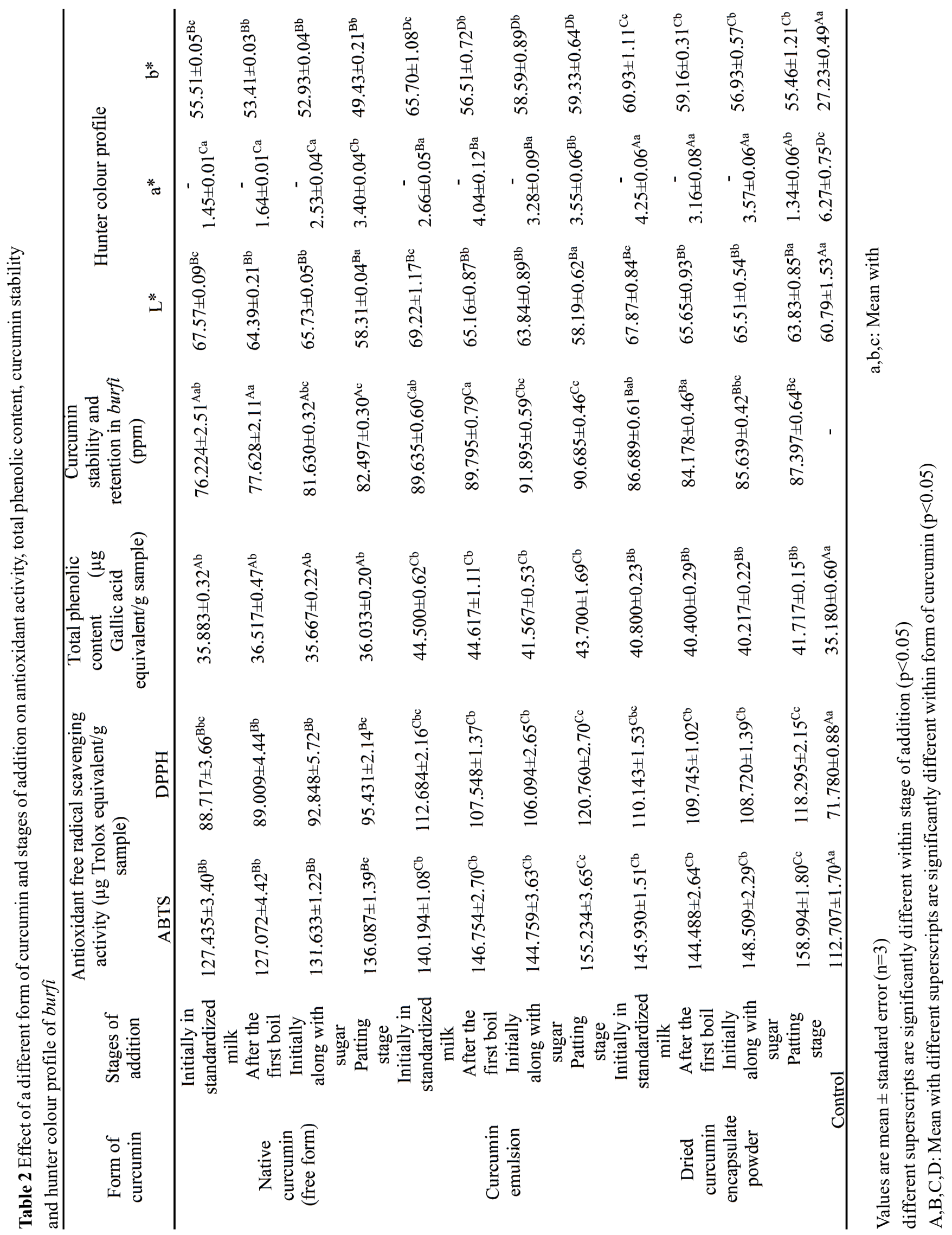


Fig. 1 Particle size distribution of curcumin emulsion of varied $\mathrm{pH}(3,6$ and 9$)$

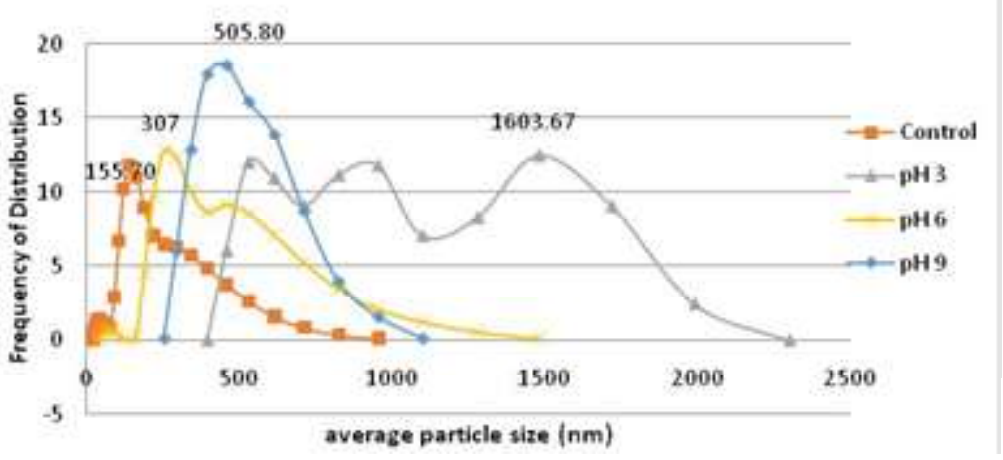

Fig. 2 Particle size distribution of curcumin emulsion with varied heat treatment $\left(63^{\circ} \mathrm{C} / 30 \mathrm{~min}\right.$ and $95^{\circ} \mathrm{C} / 10$ $\min )$

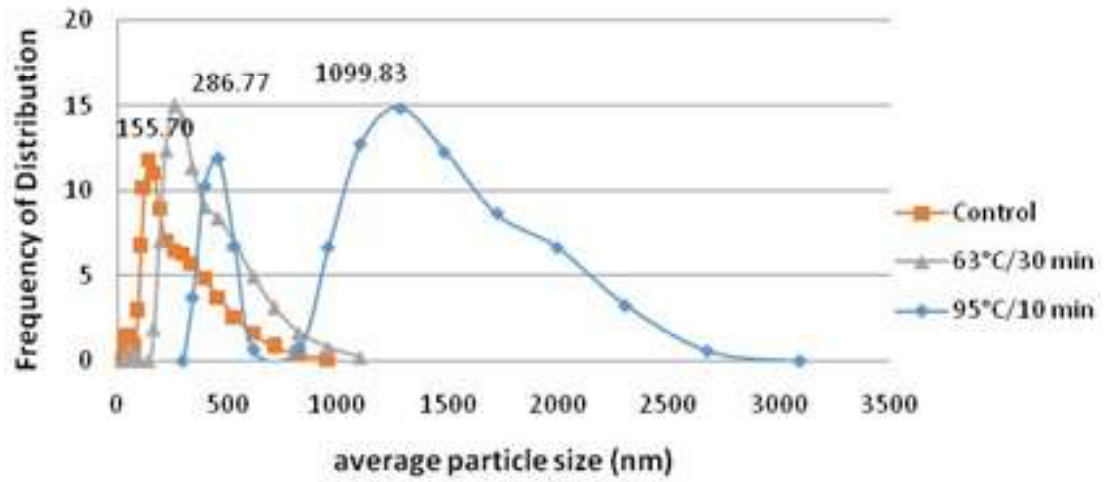

Table 3 Effect of a different form of curcumin and stages of addition on sensory attributes of burfi

\begin{tabular}{llllll}
\hline $\begin{array}{l}\text { Form of } \\
\text { curcumin }\end{array}$ & Stages of addition & Flavour & Texture & $\begin{array}{l}\text { Colour and } \\
\text { appearance }\end{array}$ & $\begin{array}{l}\text { Overall } \\
\text { acceptability }\end{array}$ \\
\hline Native & Initially in standardized milk & $7.20 \pm 0.27^{\mathrm{Aa}}$ & $7.30 \pm 0.15^{\mathrm{Aa}}$ & $7.23 \pm 0.37^{\mathrm{Aa}}$ & $7.31 \pm 0.35^{\mathrm{ABab}}$ \\
curcumin & After the first boil & $7.20 \pm 0.18^{\mathrm{Aa}}$ & $7.12 \pm 0.16^{\mathrm{Aa}}$ & $7.24 \pm 0.04^{\mathrm{Aa}}$ & $7.22 \pm 0.12^{\mathrm{ABa}}$ \\
(free form) & Initially along with sugar & $7.23 \pm 0.09^{\mathrm{Aa}}$ & $6.99 \pm 0.07^{\mathrm{Aa}}$ & $7.48 \pm 0.08^{\mathrm{Aa}}$ & $7.21 \pm 0.15^{\mathrm{ABa}}$ \\
& Patting stage & $7.28 \pm 0.15^{\mathrm{Aab}}$ & $7.13 \pm 0.19^{\mathrm{Aa}}$ & $7.37 \pm 0.19^{\mathrm{Aa}}$ & $7.36 \pm 0.07^{\mathrm{ABab}}$ \\
Curcumin & Initially in standardized milk & $6.90 \pm 0.26^{\mathrm{Aa}}$ & $7.26 \pm 0.06^{\mathrm{ABa}}$ & $7.48 \pm 0.29^{\mathrm{Aa}}$ & $7.18 \pm 0.16^{\mathrm{Aab}}$ \\
emulsion & After the first boil & $7.22 \pm 0.02^{\mathrm{Aa}}$ & $7.18 \pm 0.04^{\mathrm{ABa}}$ & $7.20 \pm 0.22^{\mathrm{Aa}}$ & $7.03 \pm 0.09^{\mathrm{Aa}}$ \\
& Initially along with sugar & $7.10 \pm 0.06^{\mathrm{Aa}}$ & $7.16 \pm 0.23^{\mathrm{ABa}}$ & $6.88 \pm 0.51^{\mathrm{Aa}}$ & $6.92 \pm 0.19^{\mathrm{Aa}}$ \\
& Patting stage & $7.53 \pm 0.15^{\mathrm{Aab}}$ & $7.29 \pm 0.05^{\mathrm{ABa}}$ & $7.18 \pm 0.31^{\mathrm{Aa}}$ & $7.08 \pm 0.20^{\mathrm{Aab}}$ \\
Dried & Initially in standardized milk & $7.37 \pm 0.20^{\mathrm{Aa}}$ & $7.19 \pm 0.18^{\mathrm{ABa}}$ & $7.30 \pm 0.05^{\mathrm{Aa}}$ & $7.20 \pm 0.09^{\mathrm{Aab}}$ \\
curcumin & After the first boil & $7.19 \pm 0.11^{\mathrm{Aa}}$ & $7.26 \pm 0.13^{\mathrm{ABa}}$ & $7.13 \pm 0.14^{\mathrm{Aa}}$ & $7.17 \pm 0.11^{\mathrm{Aa}}$ \\
encapsulate & Initially along with sugar & $7.13 \pm 0.13^{\mathrm{Aa}}$ & $7.51 \pm 0.07^{\mathrm{ABa}}$ & $7.13 \pm 0.07^{\mathrm{Aa}}$ & $7.08 \pm 0.04^{\mathrm{Aa}}$ \\
powder & Patting stage & $7.45 \pm 0.23^{\mathrm{Aab}}$ & $7.51 \pm 0.07^{\mathrm{ABa}}$ & $7.47 \pm 0.08^{\mathrm{Aa}}$ & $7.49 \pm 0.20^{\mathrm{Aab}}$ \\
& Control & $7.83 \pm 0.03^{\mathrm{Bb}}$ & $7.55 \pm 0.13^{\mathrm{Bb}}$ & $7.73 \pm 0.16^{\mathrm{Aa}}$ & $7.69 \pm 0.15^{\mathrm{Bb}}$ \\
\hline
\end{tabular}

Values are mean \pm standard error $(n=3)$

$\mathrm{a}, \mathrm{b}$ : Mean with different superscripts are significantly different within stage of addition $(\mathrm{p}<0.05)$

A,B: Mean with different superscripts are significantly different within form of curcumin $(p<0.05)$

cyclodextrin complex and reported 85 to $90 \%$ of total curcumin retention in lassi.

\section{Effect of a different form of curcumin and stages of addition on hunter colour values of burfi}

The lightness $\left(\mathrm{L}^{*}\right)$, redness-greenness $\left(\mathrm{a}^{*}\right)$ and yellownessblueness $\left(\mathrm{b}^{*}\right)$ index of the control and curcumin added burfi were presented in Table 2 . The $\mathrm{L}^{*}$ value of all the curcumin added burfi samples varied from 58.19 to 69.22 which was significantly higher than control burfi. The lightness value of burfi was associated with the extent of heat treatment which mainly depends upon the stage of addition. The initial fortification in standardized milk showed the highest lightness index with $\mathrm{L}^{*}$ value of 69.22 whereas fortification at patting stage showed the least (58.19). The $\mathrm{a}^{*}$ value of control sample was 6.27 which was significantly higher than all curcumin added burfi and ranged from -4.25 to 
Fig. 3 Particle size distribution of curcumin emulsion with different ionic concentration $(0.35 \mathrm{M} \mathrm{NaCl}, 0.70 \mathrm{M} \mathrm{NaCl}$, and $1 \mathrm{M} \mathrm{NaCl})$

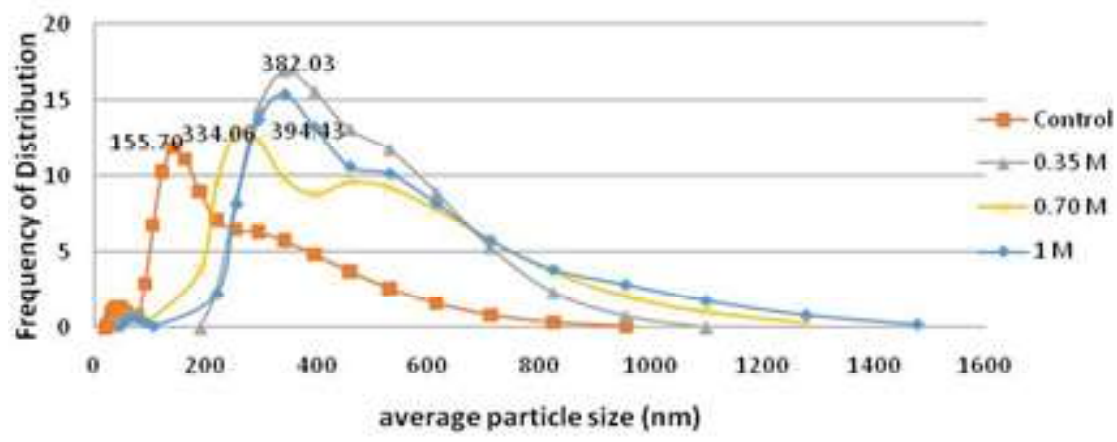

Fig. 4 In-vitro release kinetics of curcumin encapsulated burfi

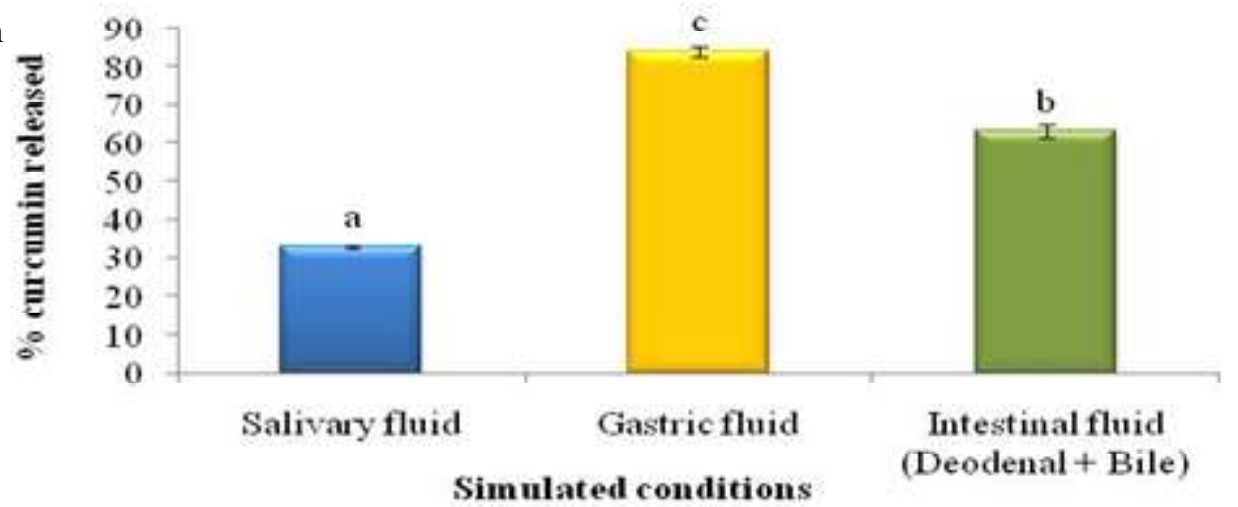

+3.55 . Both (different forms of curcumin and the stage of addition) were responsible for decreased a* value of burfi. The $\mathrm{b}^{*}$ value (yellowness-blueness index) of control sample was 27.23 that significantly increased to 65.70 in curcumin emulsion added burfi at the initial stage of addition. The emulsion and encapsulate curcumin added burfi showed significantly higher $\mathrm{b}^{*}$ value than native curcumin added burfi. This could be due to the lower retention of curcumin in burfi when added in native form. The change in the colour value of burfi was due to the addition of encapsulated curcumin. Meena (2018) has observed the $\mathrm{L}^{*}, \mathrm{a}^{*}$, and $b^{*}$ value of dried curcumin encapsulate to be $87.44,-7.49$, and 72.02 , respectively that further decreased with storage period. The addition of curcumin in milk at the initial stage of burfi preparation resulted in higher destabilization of curcumin thus released more curcumin due to the higher exposure of heat and scrapping that affected the colour values of curcumin added burfi.

\section{Effect of a different form of curcumin and stages of addition on sensorial attributes of burfi}

The average flavour score of control burfi was 7.83, which was reduced to 6.90 upon addition of curcumin (Table 3). A significant difference was observed in burfi samples fortified with different forms of curcumin added at various stages during preparation. The decreased flavour score of curcumin burfi may be attributed to the bitter taste of curcumin that mask the flavour of burfi. The body and textural scores of all the curcumin added burfi were significantly less than the control sample. A non-significant difference was observed in the colour and appearance score of curcumin added burfi and control sample. The intense yellow coloured burfi was least accepted by the sensory panellists than light yellow coloured burfi. The overall acceptability scores of curcumin added burfi ranged from 6.92 to 7.49 which were significantly less than control burfi with a mean score of 7.69. The bitter after taste and intense yellow colour decreased the overall acceptability of curcumin added burfi. The bitter taste was more pronounced in burfi added with native curcumin which was reflected in the flavour score. Burfi added with dried curcumin encapsulate at patting stage was highly acceptable with average overall acceptability score of 7.49 than other curcumin added burfi but comparatively less than the control sample. Similar, results of bitterness in burfi added with turmeric essential oil that decreased the consumer acceptability were reported by Prasad et al. (2017a). Maurya (2002) reported a decreased overall acceptance of curcumin fortified lassi due to intense yellow colour. Based on above observation the dried curcumin encapsulate was the most suitable form for incorporation in burfi that enhance the antioxidant potential but the enhancement was much higher during the patting stage of preparation.

\section{Optimization of the level of addition of dried curcumin encapsulate in burfi}

To optimize the level of addition, the burfi was incorporated with dried curcumin encapsulate at levels of $5 \%, 7.5 \%, 10 \%, 12.5 \%$, 
Fig. 5 Antifungal activity of curcumin encapsulate added burfi

\section{Antifungal activity of encapsulated curcumin added burfi}
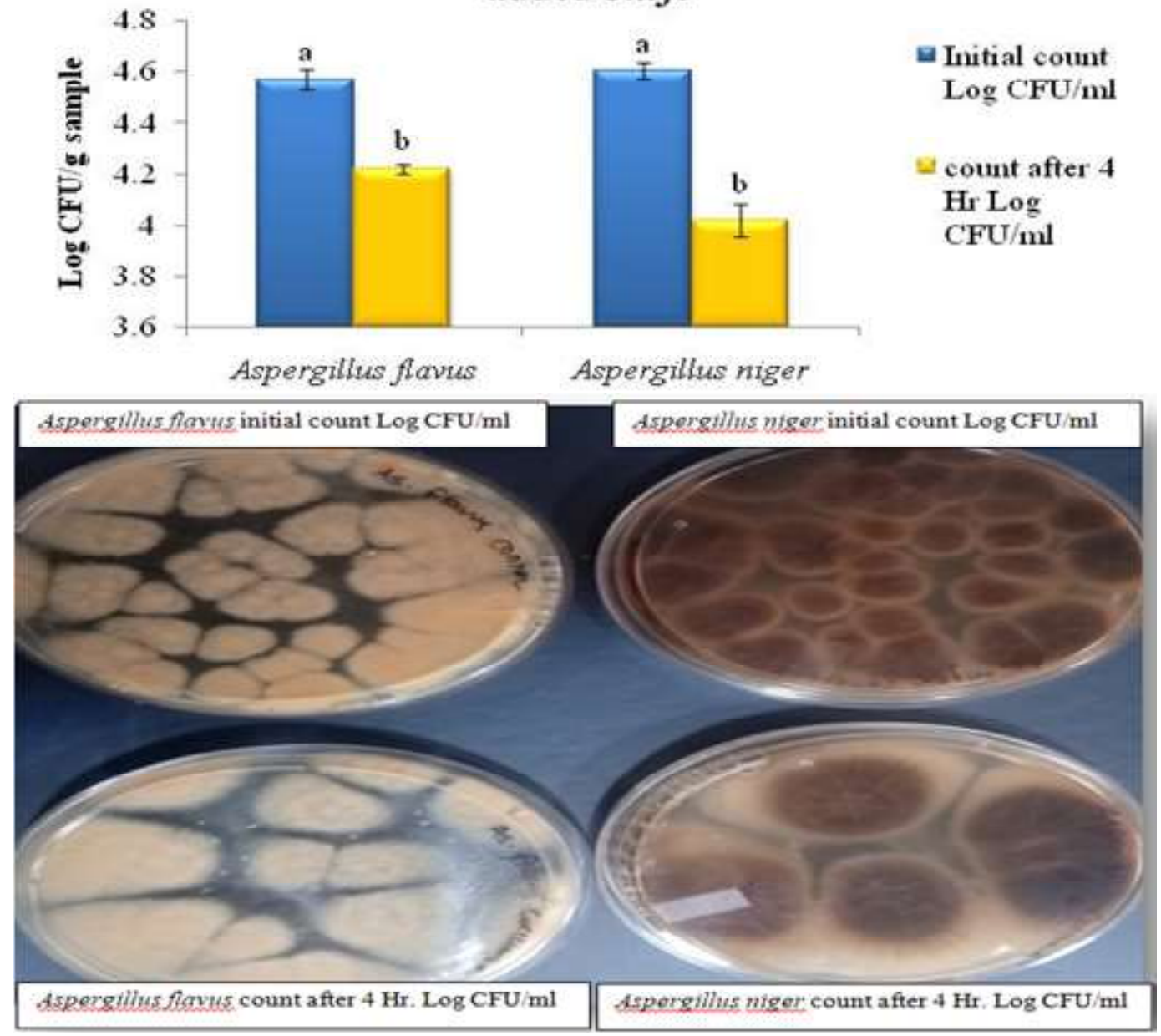

and $15 \%$ and the responses were measured in terms of antioxidant potential, hunter colour value and sensorial attributes.

\section{Effect of level of dried curcumin encapsulate on antioxidant activity and total phenolic content of burfi}

The antioxidant potential of burfi samples incorporated with different levels of dried curcumin encapsulate were analyzed by ABTS and DPPH free radical scavenging method and compared with the positive control sample containing 200 ppm BHA. The ABTS and DPPH free radical scavenging activity of curcumin encapsulate added burfi was significantly less than the positive control but increased with the extent of curcumin (Table 4). Moreover, the highest antioxidant potential was obtained at $15 \%$ level of dried curcumin encapsulate. In addition, the burfi added with $15 \%$ level of dried curcumin encapsulate was observed to have highest phenolic content of $48.317 \mu \mathrm{g}$ gallic acid equivalent/ g sample. Polyphenolic compounds are naturally present in many plants and are potential source of antioxidants (Soong and Barlow, 2004; Balasundram et al. 2006). A similar trend of increased antioxidant potential was observed in burfi with the addition of different polyphenol-rich herbs (Prasad et al. 2017a). The increase in the antioxidant potential of bread with incorporation of turmeric was observed by Lim et al. (2011).

\section{Effect of level of dried curcumin encapsulate on Hunter colour profile of burfi}

Burfi samples with different concentrations of curcumin encapsulate were evaluated for colour profile using Hunter lab colorimeter and the results were presented in Table 4 . A nonsignificant difference in $\mathrm{L}^{*}$ value was observed in burfi with highest lightness (63.268) value in 10\% curcumin encapsulate burfi. However, the $\mathrm{a}^{*}$ (redness-greenness) value of burfi showed a significant decrease with increased level of curcumin 
encapsulate. With the increased level of curcumin encapsulate a significant increase in the $b^{*}$ (yellowness-blueness) value was observed with the highest yellowness (58.174) in burfi with 15\% curcumin encapsulate. The oversaturation of yellowness at $15 \%$ curcumin encapsulates exhibits unnatural appearance of burfi, thus less accepted. Cheese curcumin showed higher yellowness index while yoghurt curcumin showed a slight greenish-yellow colour (Marcolino et al. 2011). Manoharan et al. (2012) observed increased yellowness of ice cream with addition of curcumin.

\section{Effect of level of dried curcumin encapsulate on sensorial attributes of burfi}

The sensory scores of burfi in terms of flavour, texture, colour and overall appearance perceived by sensory panellists, were reported in Table 5. The level of curcumin encapsulate showed a non-significant effect on the sensory attributes of burfi and the scores decrease beyond $10 \%$ level of curcumin encapsulates due to the over saturation of yellowness. At higher concentration curcumin encapsulate induced intense yellow colour and bitter taste in burfi thereby, limiting its overall acceptance. Kumar et al.
(2016) observed a non-significant difference in sensory analysis on 9 point hedonic scale of control and curcumin emulsion ice cream. The overall acceptability of bread was observed to be decreased with the increase in the curcumin concentration due to intense yellow crumb colour (Lim et al. 2011).

Based on antioxidant and sensory analysis, $10 \%$ level of curcumin encapsulate was found to be effective for incorporation in burfi and hence, was considered to be the optimized product with chemical composition of $14.72 \%$ moisture, $21.23 \%$ fat, $14.82 \%$ protein, $18.09 \%$ lactose, $2.81 \%$ ash and $28.33 \%$ sucrose in the final product.

\section{In-vitro release kinetics of curcumin encapsulate added burfi}

Functional benefits of optimized burfi primarily depends on the release of curcumin from encapsulate which was evaluated in simulated gastro-intestinal conditions. A 33\% of total curcumin from encapsulate present in burfi was released in salivary fluid which was further increased to around $83 \%$ in gastric fluid. The alkaline conditions in the intestinal fluid caused around $20 \%$

Table 4 Effect of level of dried curcumin encapsulate on antioxidant activity (ABTS and DPPH), total phenolic content and hunter colour profile of curcumin encapsulate added burfi

\begin{tabular}{|c|c|c|c|c|c|c|}
\hline \multirow{2}{*}{$\begin{array}{l}\text { Level of } \\
\text { addition } \\
\text { curcumin } \\
\text { encapsulates } \\
\text { (\%) }\end{array}$} & \multicolumn{2}{|c|}{$\begin{array}{c}\text { Antioxidant free radical } \\
\text { scavenging activity ( } \mu \text { g Trolox } \\
\text { equivalent/g sample) }\end{array}$} & \multirow{2}{*}{$\begin{array}{l}\text { Total phenolic } \\
\text { content }(\mu \mathrm{g} \\
\text { Gallic acid } \\
\text { equivalent/g } \\
\text { sample) }\end{array}$} & \multicolumn{3}{|c|}{ Hunter colour profile } \\
\hline & ABTS & DPPH & & $\mathrm{L}^{*}$ & $a^{*}$ & $b^{*}$ \\
\hline Control & $112.707 \pm 1.70^{\mathrm{a}}$ & $71.780 \pm 0.88^{\mathrm{a}}$ & $35.183 \pm 0.60^{\mathrm{a}}$ & $60.787 \pm 1.53^{\mathrm{a}}$ & $6.269 \pm 0.75^{b}$ & $27.230 \pm 0.49^{\mathrm{a}}$ \\
\hline $\begin{array}{l}\text { BHA (200 } \\
\text { ppm) }\end{array}$ & $200.515 \pm 3.46^{\mathrm{f}}$ & $195.304 \pm 1.20^{\mathrm{g}}$ & $34.633 \pm 0.59^{\mathrm{a}}$ & $58.910 \pm 1.92^{\mathrm{a}}$ & $4.121 \pm 0.24^{\mathrm{ab}}$ & $49.508 \pm 1.75^{\mathrm{b}}$ \\
\hline $5 \%$ & $119.182 \pm 1.96^{\mathrm{a}}$ & $103.148 \pm 0.78^{\mathrm{b}}$ & $41.167 \pm 1.11^{\mathrm{b}}$ & $62.210 \pm 0.47^{\mathrm{a}}$ & $4.424 \pm 0.34^{\mathrm{ab}}$ & $53.698 \pm 0.71^{\mathrm{bc}}$ \\
\hline $7.5 \%$ & $134.922 \pm 2.38^{\mathrm{b}}$ & $111.909 \pm 0.95^{\mathrm{c}}$ & $42.017 \pm 0.62^{\mathrm{b}}$ & $63.268 \pm 0.48^{\mathrm{a}}$ & $2.727 \pm 0.26^{\mathrm{a}}$ & $56.201 \pm 0.92^{\mathrm{c}}$ \\
\hline $10 \%$ & $150.634 \pm 1.75^{\mathrm{c}}$ & $125.439 \pm 1.41^{\mathrm{d}}$ & $43.667 \pm 0.57^{\mathrm{bc}}$ & $59.600 \pm 1.53^{\mathrm{a}}$ & $3.822 \pm 0.64^{\mathrm{a}}$ & $55.971 \pm 1.05^{\mathrm{c}}$ \\
\hline $\begin{array}{c}12.5 \% \\
15 \%\end{array}$ & $\begin{array}{l}168.404 \pm 2.12^{\mathrm{d}} \\
183.439 \pm 2.61^{\mathrm{e}}\end{array}$ & $\begin{array}{l}140.746 \pm 2.27^{\mathrm{e}} \\
152.410 \pm 1.93^{\mathrm{f}}\end{array}$ & $\begin{array}{c}45.300 \pm 0.29^{\mathrm{cd}} \\
48.317 \pm 0.39^{\mathrm{d}}\end{array}$ & $58.762 \pm 0.79^{\mathrm{a}}$ & $3.766 \pm 0.37^{\mathrm{a}}$ & $58.174 \pm 0.91^{\mathrm{c}}$ \\
\hline
\end{tabular}

Values are mean \pm standard error $(\mathrm{n}=3)$

a,b,c,d,e,f,g: Mean with different superscripts are significantly different within the level of curcumin encapsulates $(\mathrm{p}<0.05)$

Table 5 Effect of varied levels of curcumin encapsulate on sensory attributes of burfi

\begin{tabular}{lllll}
\hline $\begin{array}{l}\text { Level of addition curcumin } \\
\text { encapsulates }(\%)\end{array}$ & Flavour & Texture & $\begin{array}{l}\text { Colour and } \\
\text { Appearance }\end{array}$ & $\begin{array}{l}\text { Overall } \\
\text { acceptability }\end{array}$ \\
\hline Control & $7.81 \pm 0.04^{\mathrm{a}}$ & $7.73 \pm 0.02^{\mathrm{a}}$ & $7.79 \pm 0.09^{\mathrm{a}}$ & $7.72 \pm 0.06^{\mathrm{ab}}$ \\
$5 \%$ & $8.01 \pm 0.07^{\mathrm{a}}$ & $7.71 \pm 0.11^{\mathrm{a}}$ & $7.73 \pm 0.04^{\mathrm{a}}$ & $7.70 \pm 0.06^{\mathrm{ab}}$ \\
$7.5 \%$ & $7.99 \pm 0.20^{\mathrm{a}}$ & $7.79 \pm 0.15^{\mathrm{a}}$ & $7.76 \pm 0.18^{\mathrm{a}}$ & $7.79 \pm 0.10^{\mathrm{ab}}$ \\
$10 \%$ & $7.88 \pm 0.25^{\mathrm{a}}$ & $8.12 \pm 0.07^{\mathrm{a}}$ & $7.84 \pm 0.22^{\mathrm{a}}$ & $7.93 \pm 0.12^{\mathrm{b}}$ \\
$12.5 \%$ & $7.69 \pm 0.04^{\mathrm{a}}$ & $7.66 \pm 0.22^{\mathrm{a}}$ & $7.47 \pm 0.06^{\mathrm{a}}$ & $7.45 \pm 0.06^{\mathrm{a}}$ \\
$15 \%$ & $7.84 \pm 0.05^{\mathrm{a}}$ & $7.89 \pm 0.21^{\mathrm{a}}$ & $7.30 \pm 0.03^{\mathrm{a}}$ & $7.45 \pm 0.04^{\mathrm{a}}$ \\
\hline
\end{tabular}

Values are mean \pm standard error $(n=3)$

a,b: Mean with different superscripts are significantly different within the level of curcumin encapsulates $(p<0.05)$ 
Fig. 6 Changes in the antioxidant activity of control and encapsulated curcumin burfi during storage
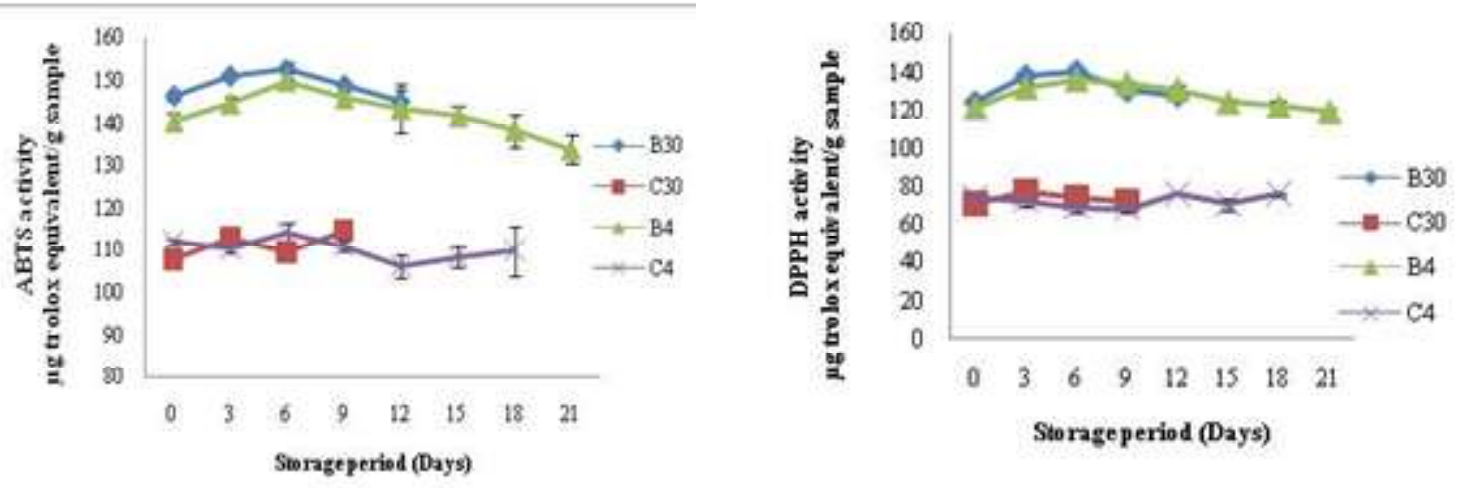

degradation of free curcumin released from encapsulate and the remaining $63 \%$ free curcumin was found to be stable at the end of intestinal digestion (Figure 4). Sari et al. (2015) determined the invitro release behaviour of curcumin nanoemulsion and observed that the emulsion had excellent stability in gastric fluid with the release of only $8.48 \%$ of total curcumin, but undergoes destabilization in intestinal digestion with the release of $77.75 \%$ curcumin from the emulsion. The release of curcumin from encapsulated added burfi in gastric fluid is based on the behaviour of whey protein during the processing of burfi. The heat treatment results in the denaturation of whey protein (WPC-80) known for higher digestibility, readily digested in gastric condition and thus released the curcumin present inside encapsulate.

\section{Antifungal activity of curcumin encapsulate added burfi}

The curcumin encapsulate added burfi was evaluated for its antifungal activity against two major milk sweet spoilage causing moulds viz., Aspergillus flavus and Aspergillus niger and with $0.35 \mathrm{Log}$ CFU $/ \mathrm{ml}$ and $0.47 \mathrm{Log}$ CFU/ml reduction in the Aspergillus flavus and Aspergillus niger, the curcumin encapsulate present inside the burf $i$ was found to be effective against fungal spoilage (Figure 5). Wang et al. (2009) studied the inhibitory effect of microcurcumin encapsulate against spoilage microorganisms. The highest inhibition was found in Aspergillus niger and thus indicates the efficacy of curcumin against fungal microorganisms.

\section{Storage stability and shelf life of curcumin encapsulate added burfi}

\section{Changes in the antioxidant activity of control and curcumin encapsulate added burfi during storage}

The ABTS and DPPH free radical scavenging activity of curcumin encapsulate added burfi was increased up to 6 days followed by continuous decrease throughout the storage period as depicted in Figure 6. A non-significant difference in the antioxidant activity of curcumin encapsulate burfi was observed with storage irrespective of storage temperature. The initial increase in the antioxidant potential of curcumin encapsulate burfi was due to the release of remaining curcumin from encapsulate with the storage. This released curcumin scavenges free radicals with

storage period thus, caused further reduction in the antioxidant activity. A similar finding of control release of curcumin from hydrogel during storage was observed by Nakagawa et al. (2013).

\section{Changes in the physicochemical parameters of control and curcumin encapsulate added burfi during storage}

Control and the curcumin encapsulate added burfi were analysed for the physicochemical changes viz., free fatty acid (FFA) content, hydroxylmethylfurfural (HMF), thiobarbituric acid (TBA) value, water activity and acidity during storage. The FFA content was significantly increased with storage period and higher FFA content was observed at $30 \pm 1^{\circ} \mathrm{C}$ than $4 \pm 1^{\circ} \mathrm{C}$ storage temperature (Figure 7). At $30 \pm 1{ }^{\circ} \mathrm{C}$, the initial FFA content in control and curcumin encapsulate added burfi was 3.68 and $4.6 \mu$ equivalent oleic acid/g burfi sample respectively which was significantly increased to 6.88 and $8.12 \mu$ equivalent oleic acid/g burfi sample within 9 days of storage. The HMF content indicates the extent of Maillard browning reaction during storage. The HMF formation was significantly higher in control and curcumin encapsulate burfi stored at $30 \pm 1{ }^{\circ} \mathrm{C}$ than the samples at $4 \pm 1^{\circ} \mathrm{C}$ storage. At $30 \pm 1^{\circ} \mathrm{C}, \mathrm{HMF}$ content of curcumin encapsulate burfi reached to $28.98 \mu$ moles $/ 100 \mathrm{~g}$ TS in 12 days of storage. The nonsignificant difference in the HMF content of control and the curcumin encapsulate added burfi indicates a similar extent of browning reaction in both samples. The lipid oxidation (measured in terms of TBA value) was observed to be higher at $30 \pm 1{ }^{\circ} \mathrm{C}$ temperature as compared with the oxidation at $4 \pm 1^{\circ} \mathrm{C}$ storage. The water activity showed a non-significant difference throughout the storage period with initial decrease in the activity of burfi samples up to 3 days of storage. A significant increase in acidity of control and curcumin encapsulate burfi was observed with increased storage period at both temperatures. The results are in line with the observations of Chawla et al. (2015) who reported a significant increase in the FFA content, HMF and acidity with decreased water activity throughout the storage period in Doda burfi.

Changes in the sensory attributes of control and curcumin encapsulate added burfi during storage 

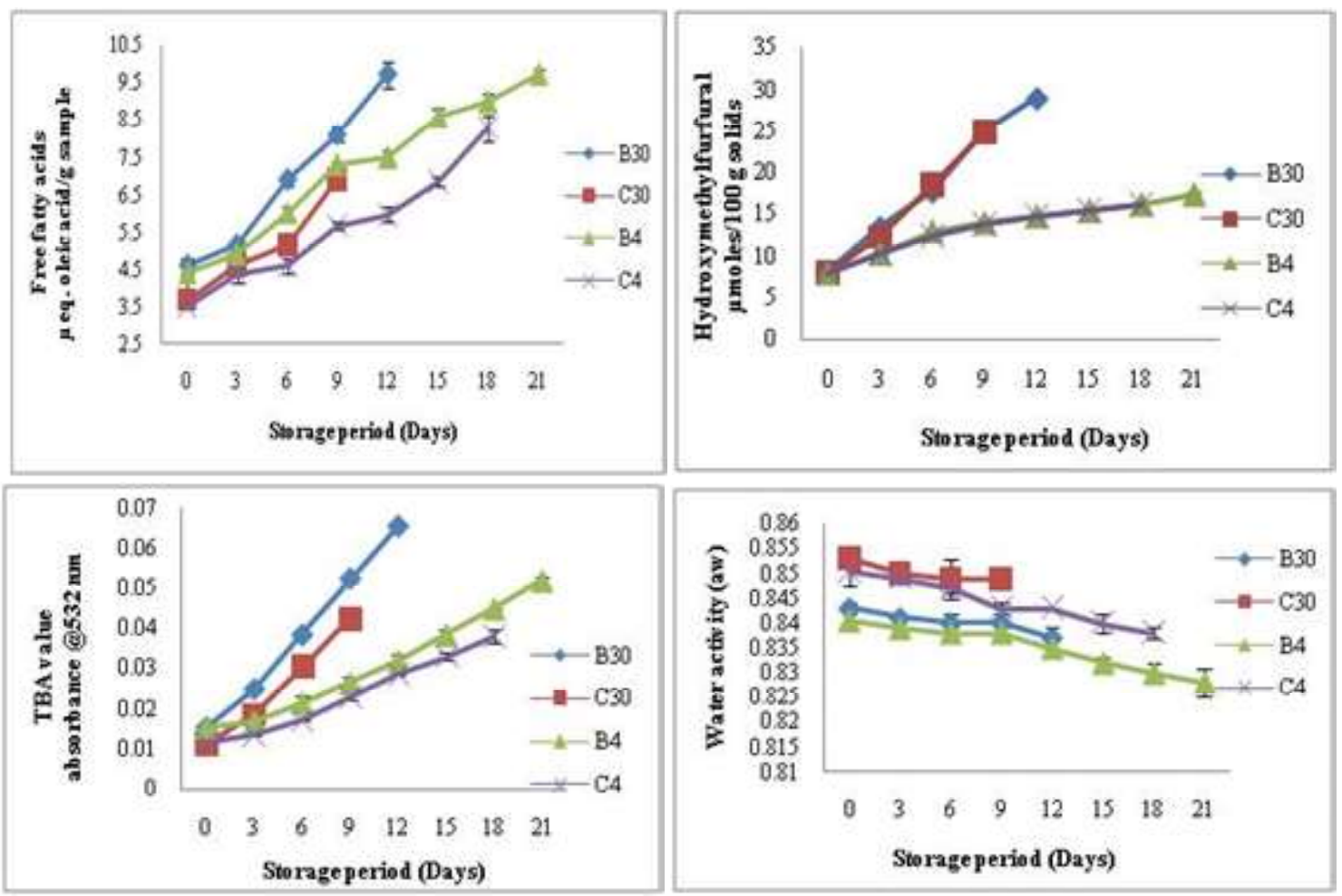

Fig. 7 Changes in the free fatty acids, hydroxymethylfurfural, thiobarbituric acid, water activity and acidity of control and encapsulated curcumin burfi during storage

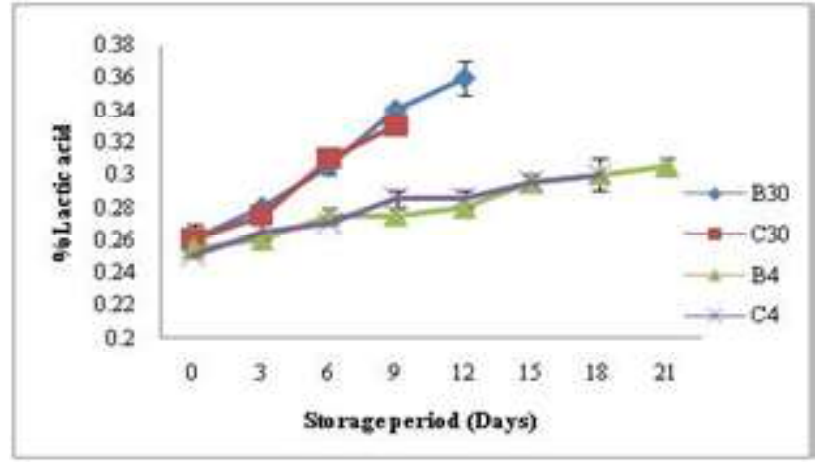

As depicted in Figure 8, the flavour score of control and the curcumin encapsulate added burfi stored at $4 \pm 1{ }^{\circ} \mathrm{C}$ was significantly decreased from 7.55 and 7.60 to 6.85 and 6.65 within 18 and 21 days of storage respectively. A significant variation in the body and texture score of samples was observed during the storage period and was decreased to as low as 6.50 in curcumin encapsulate added burfi after 21 days, while the control burfi had scored 6.70 at the end of 18 days of storage. Moreover, a similar trend in colour, appearance score and overall acceptability was also observed throughout the storage period. The overall acceptability score declined from 7.60 to 6.80 in control burfi after 18 days of storage, whereas it was reduced to 6.65 after 21 days of storage in the burfi added with curcumin encapsulate. A non-significant difference was observed in all the sensorial attributes of control and curcumin encapsulate added burfi during the entire storage period at $30 \pm 1^{\circ} \mathrm{C}$. The decrease in the sensorial attributes of burfi samples during storage was due to the evaporative loss of moisture and the oxidative and physical- chemical changes. Prasad et al. (2017b) observed a decrease in the sensorial attributes of herbal burfi during storage due to the excessive hardness of sample in the refrigerated condition. The results observed are in agreement with the findings of Chawla et al. (2015) in Doda burfi.

\section{Changes in the instrumental textural attributes of control and curcumin encapsulate added burfi during storage}

The results revealed that the hardness of control and curcumin encapsulate added burfi stored at $4 \pm 1{ }^{\circ} \mathrm{C}$ was significantly increased from $54.58 \mathrm{~N}$ and $46.78 \mathrm{~N}$ to $73.87 \mathrm{~N}$ and $80.25 \mathrm{~N}$ in 18 and 21 days of storage respectively as shown in Figure 9. A similar increased trend was observed in adhesiveness, cohesiveness, gumminess and chewiness while springiness was found to be decreased throughout the storage. The resilience showed a non-significant difference in burfi sample stored at different temperatures. These textural changes were less 
Fig. 8 Changes in the sensorial attributes of control and encapsulated curcumin burfi during storage
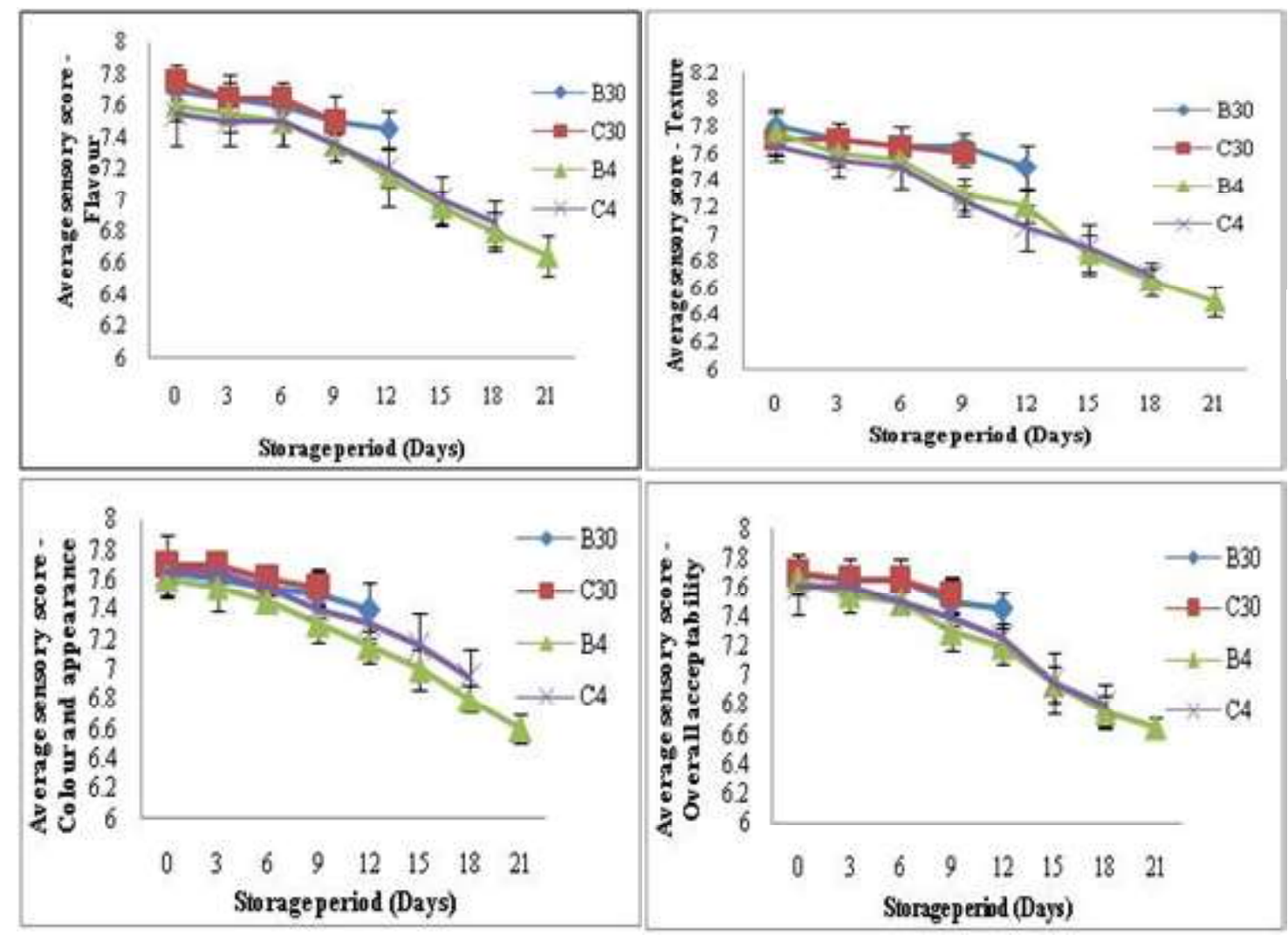

Fig. 9 Changes in the
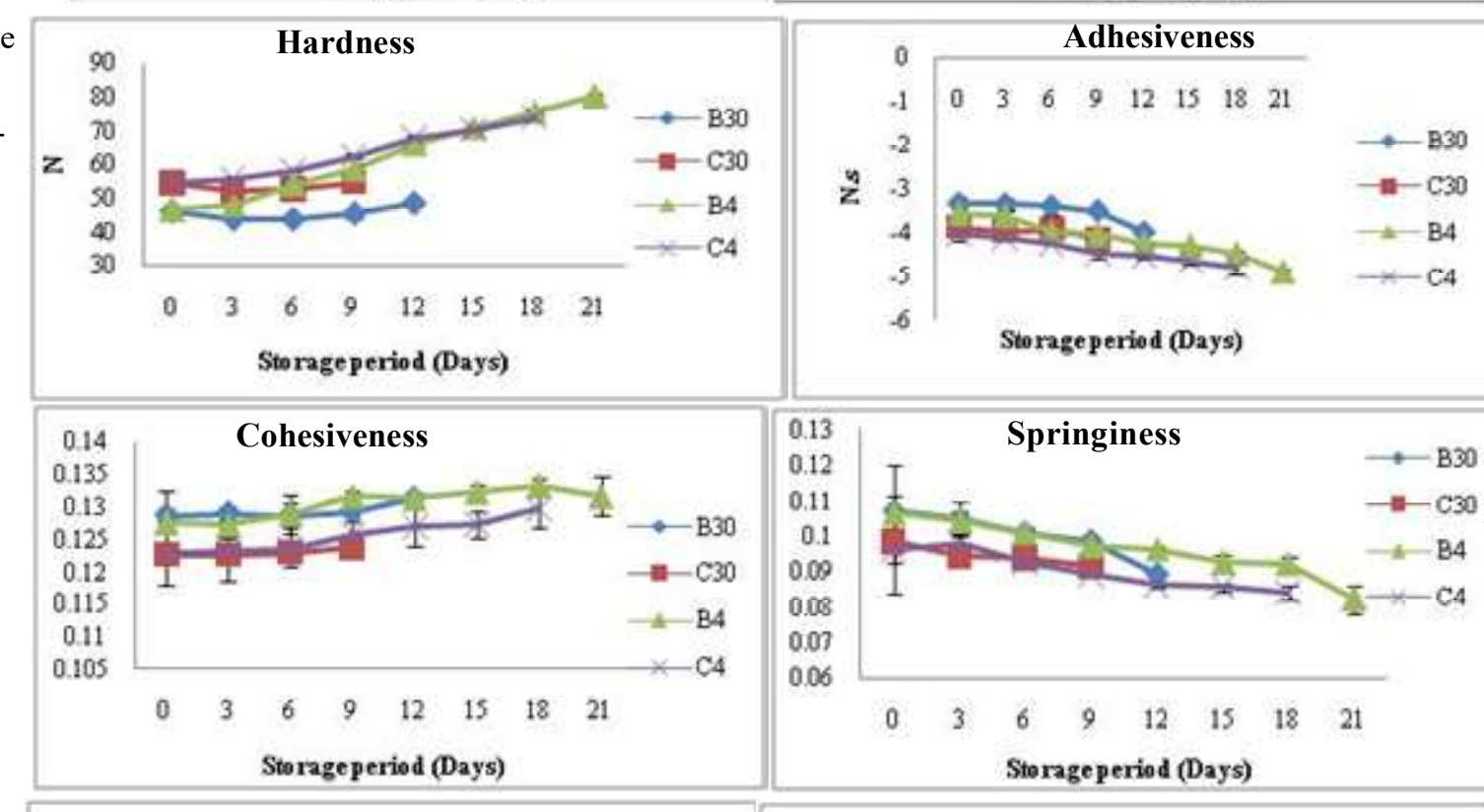

textural attributes of control and encapsulated curcumin burfi during storage
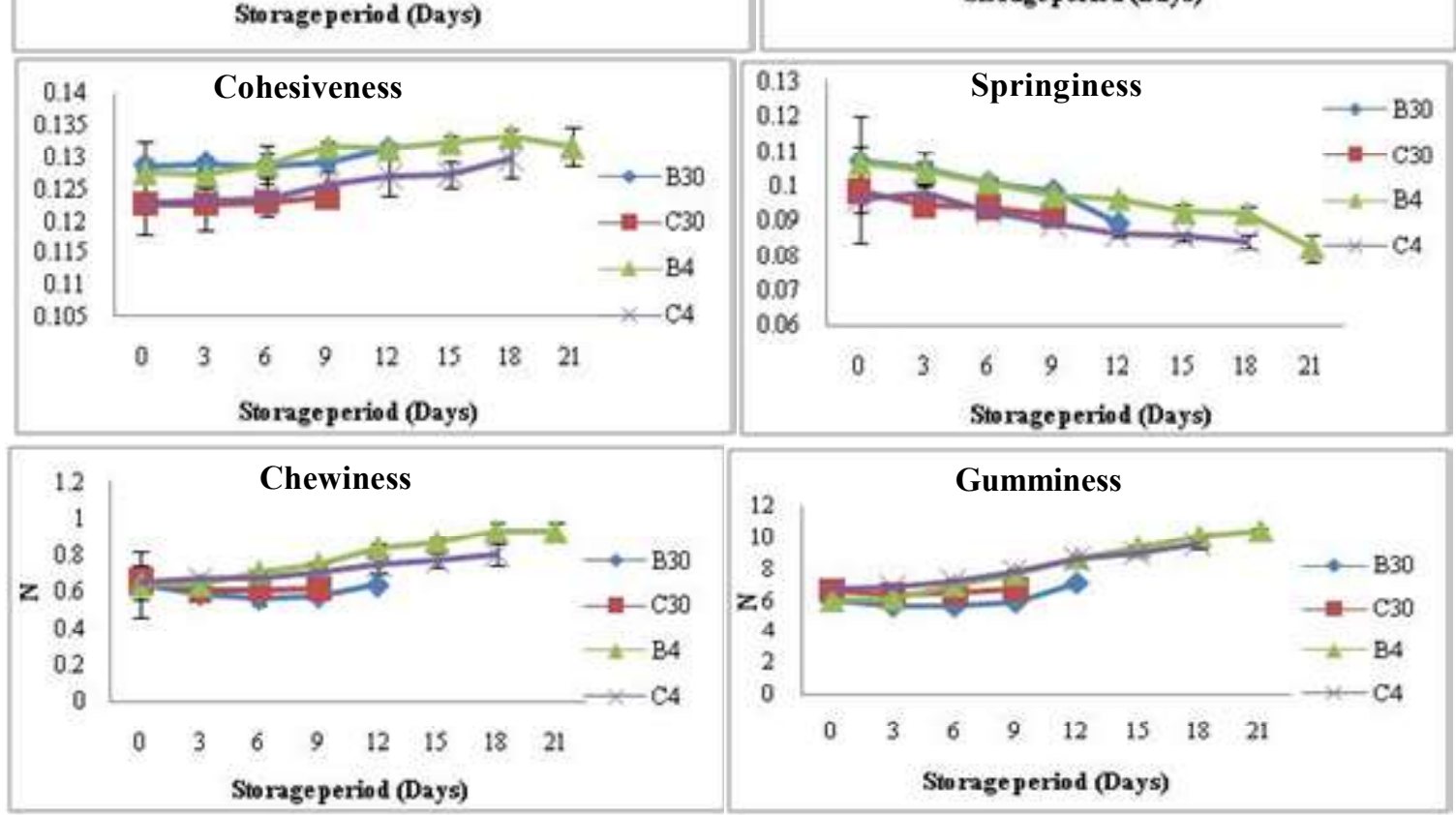


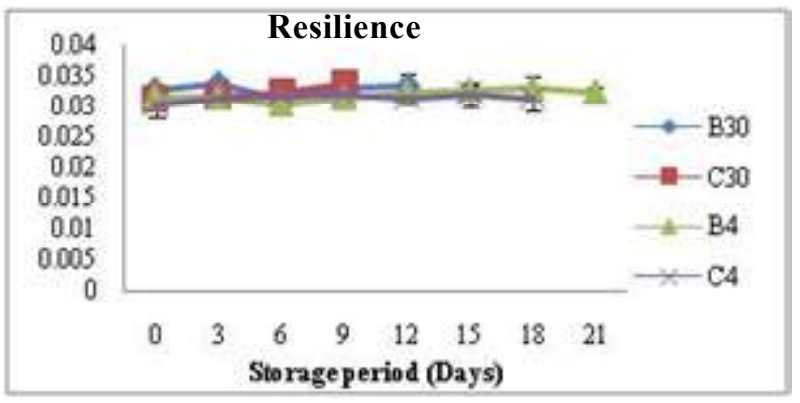

pronounced in burfi stored at $30 \pm 1^{\circ} \mathrm{C}$ as compared to sample kept at refrigerated temperature

$\left(4 \pm 1^{\circ} \mathrm{C}\right)$. The textural change observed in burfi samples was due to the evaporation of moisture from the product. Arora et al.
(2007) reported a significant increase in the hardness of lowcalorie sweetener added burfi from $62.21 \mathrm{~N}$ to $89.18 \mathrm{~N}$ during one week storage under refrigerated temperature. Chawla et al. (2015) observed a significant variation in hardness, adhesiveness, cohesiveness and gumminess of Doda burfi kept at $30 \pm 1^{\circ} \mathrm{C}$ storage temperature.

\section{Changes in the hunter colour profile of control and curcumin encapsulate added burfi during storage}

The results presented in Figure 10 revealed that the lightness value ( $\mathrm{L}^{*}$ ) of the control and curcumin encapsulate added burfi decreased significantly with storage. The extent of decrease in lightness value was more pronounced at $30 \pm 1^{\circ} \mathrm{C}$ as compared to $4 \pm 1^{\circ} \mathrm{C}$ storage temperature. The $\mathrm{a}^{*}$ value of curcumin encapsulate

Fig. 10 Changes in the hunter colour profile of control and e $\mathrm{n} \mathrm{c}$ a p s u 1 a t e d curcumin burfi
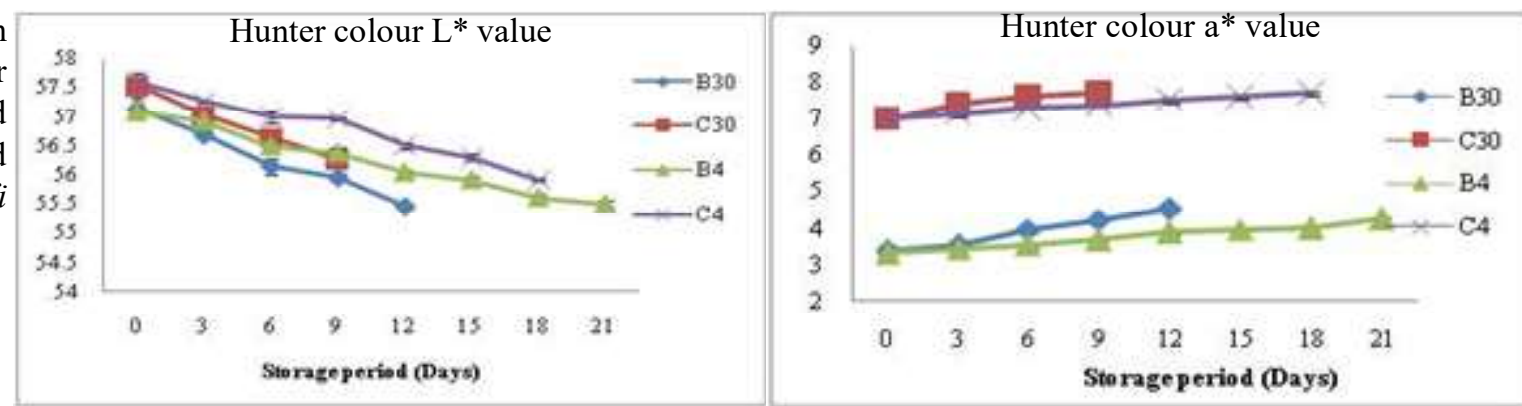
during storage

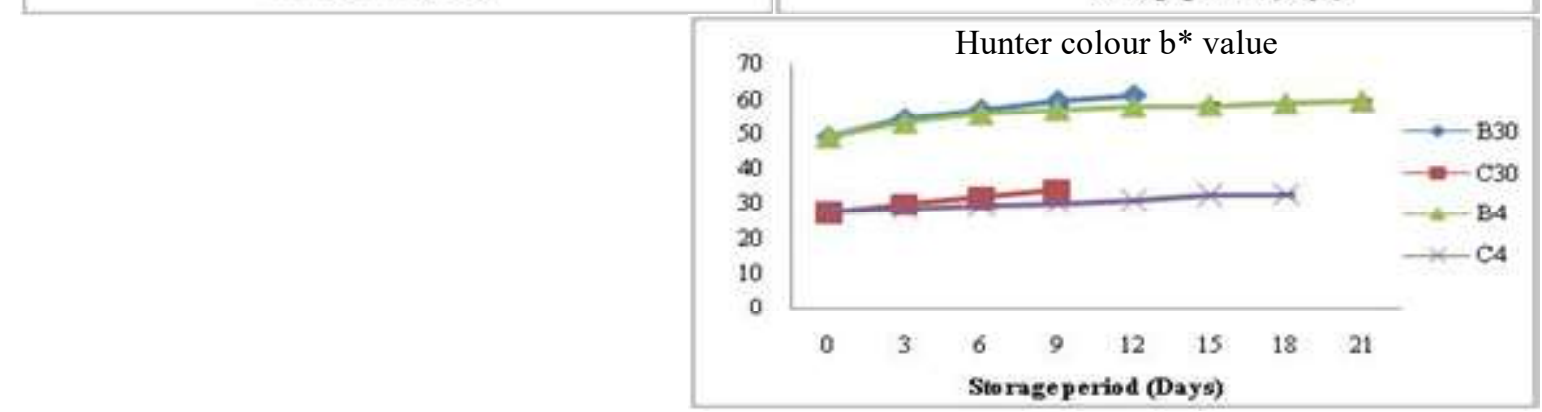

Fig. 11 Changes in the microbiological count of control and encapsulated curcumin burfi during storage
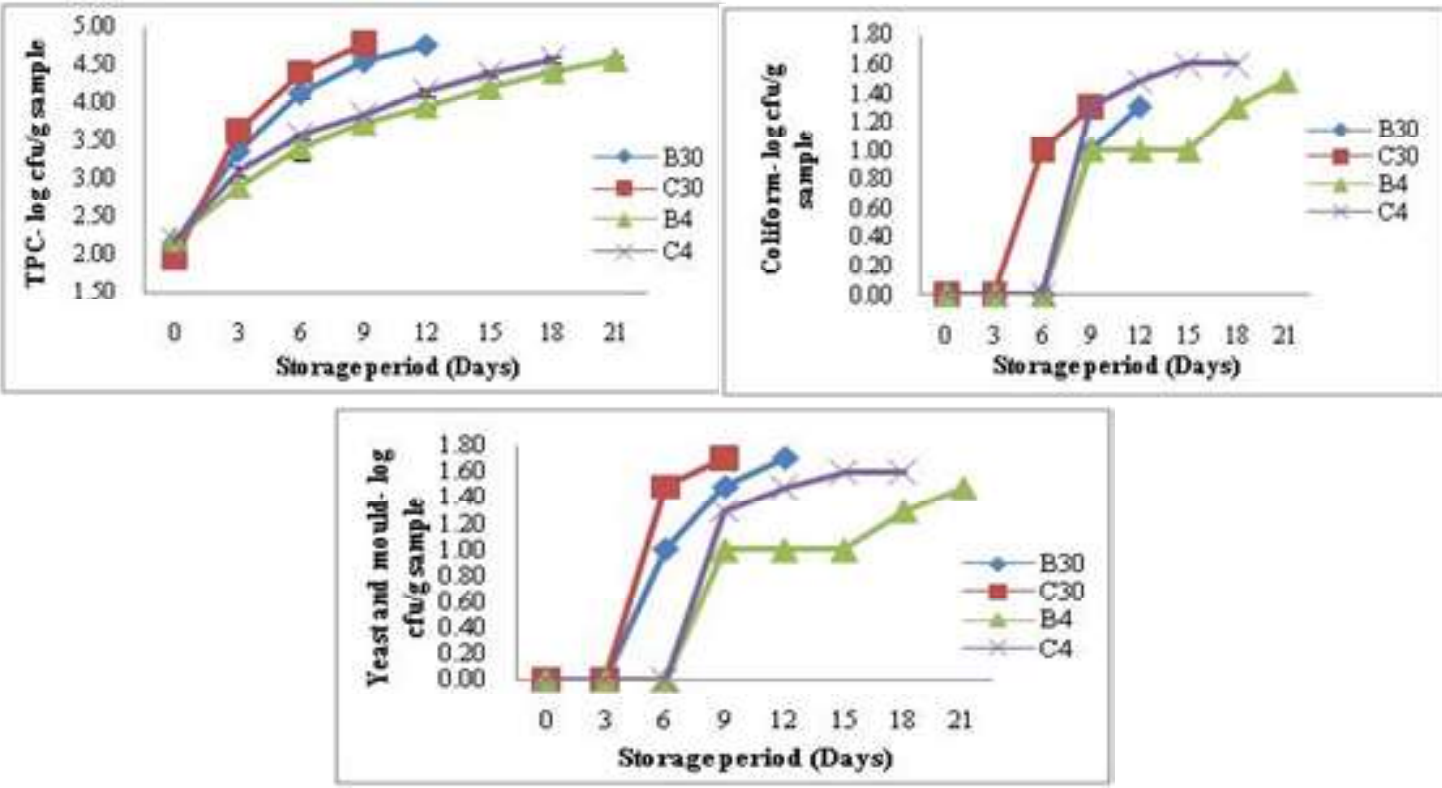
added burfi was significantly increased from 3.38 and 3.31 to 4.52 and 4.32 within 12 and 21 days of storage at $30 \pm 1^{\circ} \mathrm{C}$ and $4 \pm 1^{\circ} \mathrm{C}$ temperature respectively. The $\mathrm{b}^{*}$ value was found to be increased during storage period. The changes in burfi samples may be due to Maillard browning reactions. Arora et al. (2010) observed a decreased lightness value of artificial sweetener added burfi with increased storage period. The increase in $a^{*}$ value with increase in storage temperature and time have been reported by Gothwal and Bhavdasan (1991) and Arora et al. (2010) in khoa and artificial sweetener added burfi, respectively.

\section{Changes in the microbiological count of control and curcumin encapsulate added burfi during storage}

The changes in the microbiological counts i.e., total plate count (TPC), coliform count, yeast and mould count of burfi samples were evaluated throughout the storage period as revealed in Figure 11. A rapid microbial growth was observed in the control burfi sample as compared to the curcumin encapsulate added burfi. A similar total plate count was observed in control (after 9 days) and curcumin encapsulate added burfi (after 12 days) at $30 \pm 1^{\circ} \mathrm{C}$ storage. The visible yeast and mould growth was also observed after 9 and 12 days of storage at $30 \pm 1{ }^{\circ} \mathrm{C}$ in control and curcumin encapsulate added burfi. The coliform count was observed to be increased to $1.30 \mathrm{Log} \mathrm{CFU} / \mathrm{g}$ in curcumin encapsulate added burfi after 12 days of storage but no count was seen upto 6 days of storage at $30 \pm 1^{\circ} \mathrm{C}$. Thus, the results revealed that the antimicrobial and antifungal activity of curcumin restricts or delays the growth of spoilage-causing microorganisms and thus extends the shelf life of curcumin encapsulate added burfi upto 3 days as depicted in Figure 11. Hosny et al. (2011) observed the curcumin addition in Karish cheese could be an effective mean to protect it from spoilage and pathogenic microorganisms.

\section{Conclusions}

In this work, different forms of curcumin were added in burfi. The study concluded that the antioxidant activity and total phenolic content of curcumin added burfi were higher than the control. The highest antioxidant activity was observed in burfi sample added with curcumin encapsulate at patting stage. It was also observed that the curcumin addition affected the hunter colour profile of burfi with the least colour variation observed at patting stage. The dried curcumin encapsulate added burfi was highly accepted by the sensory panel. Thus, the dried curcumin encapsulate added at patting stage of burfi was selected for incorporation due to higher antioxidant potential. The curcumin encapsulate added at different concentrations showed increased $b^{*}$ value with extent of addition. The overall acceptability of curcumin encapsulate added burfi significantly decreased beyond $10 \%$ addition and thus, the addition of curcumin encapsulates at $10 \%$ level was selected for incorporation in burfi. The encapsulated curcumin burfi was found to be effective against fungal spoilage-causing microorganisms. The in-vitro release behaviour revealed that $63 \%$ curcumin was found to be stable after the end of intestinal digestion. The free radical scavenging activity of encapsulated curcumin burfi was increased upto 6 days of storage. The encapsulated curcumin added burfi was observed with a shelf life of 12 days at $30 \pm 1^{\circ} \mathrm{C}$. The storage life was observed to be 18 and 21 days for control and curcumin encapsulated burfi at $4 \pm 1^{\circ} \mathrm{C}$.

\section{Acknowledgements}

Director, ICAR-NDRI (Karnal), is duly acknowledged for providing all the research facilities. Authors are also thankful to M/s Plant Lipids Pvt. Ltd. Kolenchery, Cochin, Kerala (India) and $\mathrm{M} / \mathrm{s}$ Globex Enterprises, Delhi, India for providing curcumin and whey protein-80, respectively.

\section{References}

Arora S, Singh VP, Yarrakula S, Gawande H, Narendra K, Sharma V, Sharma GS (2007) Textural and microstructural properties of burfi made with various sweeteners. J Texture Stud 38: 684-697

Arora S, Gawande V, Wadhwa BK, Sharma H, George V, Sharma GS, Singh AK (2010) The development of burfi sweetened with aspartame. Int J Dairy Technol 63: 127-135

ASTA (1985) Official Methods American Spice Trade Association. Englewood Cliff, New Jersey

Balasundram N, Sundram K and Samman S (2006) Phenolic compounds in plants and agri-industrial by-products: Antioxidant activity, occurrence, and potential uses. Food Chem 99: 191-203

Bhatele ID (1983) Studies on the packaging and preservation of burfi. $\mathrm{PhD}$ thesis, Kurukshetra University, Kurukshetra, India

Bourassa P, N'Soukpoe-Kossi CN, Tajmir-Riahi HA (2013) Binding of vitamin A with milk $\alpha$-and $\beta$-caseins. Food Chem 138: 444-453

Brand-Williams W, Cuvelier ME, Berset CLWT (1995) Use of a free radical method to evaluate antioxidant activity. LWT - Food Sci Technol 28: 25-30

Chawla R, Singh AK, Patil GR (2015) Shelf life enhancement of functional doda burfi (Indian milk cake) with bio-preservatives application. Int J Res Sci Technol 5: 26-40

De S (1989) Butteroil. In: Outlines of Dairy Technology. Oxford University Press, New Delhi 110 001. Pp 174-181

Deeth HC, Fitz-Gerald CH (1975) A convenient method for determining the extent of lipolysis in milk. Australian J Dairy Technol 30: 109111

Garti N (2003) Microemulsions as microreactors for food applications. Curr Opin Colloid Interface Sci 8: 197-211

Gothwal PP, Bhavdasan MK (1991) Studies on the browning characteristics in dairy products. Indian J Dairy Sci 45: 146-151

Herrero-Barbudo MC, Granado-Lorencio F, Blanco-Navarro I, PérezSacristán B, Olmedilla-Alonso B (2009) Applicability of an in vitro model to assess the bioaccessibility of vitamins $A$ and $E$ from fortified commercial milk. Int Dairy J 19: 64-67

Hosny IM, Kholy WI, Murad HA, Dairouty RK (2011) Antimicrobial activity of Curcumin upon pathogenic microorganisms during manufacture and storage of a novel style cheese "Karishcum". J American Sci 7: 611-618

IS: SP: 18 - (Part XI) (1981) Handbook of food analysis - Dairy Products (Part XI). Bureau of Indian Standards, Manak Bhavan, New Delhi 
Jayaprakasha GK, Rao JL, Sakariah KK (2006) Antioxidant activities of curcumin, demethoxycurcumin and bisdemethoxycurcumin. Food Chem 98: 720-724

Kakkar V, Singh S, Singla D, Kaur IP (2011) Exploring solid lipid nanoparticles to enhance the oral bioavailability of curcumin. Mol Nutr Food Res 55: 495-503

Keeney M, Bassette R (1959) Detection of intermediate compounds in the early stages of browning reaction in milk products. J Dairy Sci 42: $945-960$

Kumar DD, Mann B, Pothuraju R, Sharma R, Bajaj R (2016) Formulation and characterization of nanoencapsulated curcumin using sodium caseinate and its incorporation in ice cream. Food Funct 7: 417-424

Lim HS, Park SH, Ghafoor K, Hwang SY, Park J (2011) Quality and antioxidant properties of bread containing turmeric (Curcuma longa L.) cultivated in South Korea. Food Chem 124: 1577-1582

Lodh J, Prasad W, Khamrui K (2018) Optimization of heat treatment and curcumin level for the preparation of anti-oxidant rich ghee from fermented buffalo cream by Central Composite Rotatable Design. J Food Sci Technol. https://doi.org/10.1007/s13197-018-3098-x

Madene A, Jacquot M, Scher J and Desobry S (2006) Flavour encapsulation and controlled release-a review. Int J Food Sci Technol 41: 1-21

Maheshwari RK, Singh AK, Gaddipati J, Srimal RC (2006) Multiple biological activities of curcumin: a short review. Life Sci 78: 2081-2087

Maizura M, Aminah A, Wan-Aida WM (2011) Total phenolic content and antioxidant activity of kesum (Polygonum minus), ginger (Zingiber officinale) and turmeric (Curcuma longa) extract. Int Food Res J 18: 526-531

Manoharan A, Ramasamy D, Dhanalashmi B, Gnanalashmi KS, Thyagarajan D (2012) Studies on sensory evaluation of Curcumin powder as natural color for butterscotch flavor ice cream. Indian J Drugs Dis 1: 43-46

Marcolino VA, Zanin GM, Durrant LR, Benassi MDT, Matioli G (2011) Interaction of curcumin and bixin with $\beta$-cyclodextrin: complexation methods, stability, and applications in food. J Agric Food Chem 59: $3348-3357$

Maurya NK (2012) Development of technology of curcumin fortified lassi with enhanced functional attributes. M.Tech. Thesis, ICAR- National Dairy Research Institute (Deemed University), Karnal, India
Meena S (2018) Technological intervention for preparation of spray dried curcumin encapsulate. M.Tech. Thesis, ICAR- National Dairy Research Institute (Deemed University), Karnal, India

Nakagawa K, Sowasod N, Tanthapanichakoon W, Charinpanitkul T (2013) Hydrogel based oil encapsulation for controlled release of curcumin by using a ternary system of chitosan, kappa-carrageenan, and carboxymethylcellulose sodium salt. LWT-Food Sci Technol 54: 600-605.

Neves MIL, Desobry-Banon S, Perrone IT, Desobry S, Petit J (2019) Encapsulation of curcumin in milk powders by spray-drying: Physicochemistry, rehydration properties, and stability during storage. Powder Technol 345: 601-607

Pan K, Luo Y, Gan Y, Baek S J, Zhong Q (2014) pH-driven encapsulation of curcumin in self-assembled casein nanoparticles for enhanced dispersibility and bioactivity. Soft Matter 10: 6820-6830

Prasad W, Khamrui K, Mandal S, Badola R (2017a) Anti-oxidative, physicochemical and sensory attributes of burû affected by incorporation of different herbs and its comparison with synthetic anti-oxidant (BHA). J Food Sci Technol 54: 3802-3809

Prasad W, Khamrui K and Sheshgiri S (2017b) Effect of packaging materials and essential oils on the storage stability of Burû, a Dairy Dessert. J Packag Technol Res 1: 181-192

Rao J, McClements DJ (2011) Food-grade microemulsions, nanoemulsions and emulsions: fabrication from sucrose monopalmitate and lemon oil. Food Hydrocolloids 25: 1413-1423

Re R, Pellegrini N, Proteggente A, Pannala A, Yang M and Rice-Evans C (1999) Antioxidant activity applying an improved ABTS radical cation decolorization assay. Free Radical Biol Med 26: 1231-1237

Sari TP, Mann B, Kumar R, Singh RRB, Sharma R, Bhardwaj M, Athira S (2015) Preparation and characterization of nanoemulsion encapsulating curcumin. Food Hydrocolloids 43: 540-546

Soong YY, Barlow PJ (2004) Antioxidant activity and phenolic content of selected fruit seeds. Food Chem 88: 411-417

Wang Y, Lu Z, Wu H, Lv F (2009) Study on the antibiotic activity of microcapsule curcumin against foodborne pathogens. Int J Food Microbiol 136 71-74 